
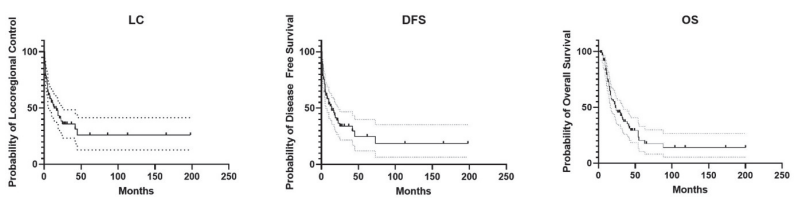

Abstract 1112 Figure 1 Kaplan Meier curves for LC, DFS and OS

4.4\%. After a median follow-up of 10 months (range 1-199), the 2-year actuarial local control rate (LC), the 2-year disease free survival rate (DFS) and the overall survival rate (OS) were 42.2\%, 40\%, and 36.7\%, respectively. Kaplan-Meier curves were computed and reported in figure 1.

Conclusion* A diverse spectrum of radiotherapy options to exclusively treat patients affected by VC was reported. Clinical outcomes are still confirmed to be poor. The results suggest the clinical evaluation of the impact of treatment standardisation, in terms of doses and volumes, in a further perspective study.

\section{INGUINOFEMORAL LYMPH NODE DISSECTION TECHNIQUE}

C Pappa*, S Smith, HJ Jiang, M Alazzam. Gynaecological Oncology, Oxford

\subsection{6/ijgc-2021-ESG0.637}

Introduction/Background* The cornerstone of treatment in early-stage squamous cell carcinoma (SCC) of the vulva is wide local excision with elective uni- or bi-lateral inguinofemoral lymphadenectomy.

Methodology Draw a line between the anterior superior iliac spine (ASIS) and pubic tubercle. Measure $3 \mathrm{~cm}$, medial to ASIS to mark the lateral dissection border. Draw a 90-degree line, $6-7 \mathrm{~cm}$ down towards the thigh and repeat the same step from the pubic tubercle. Join the two-end point to draw the incision for the groin nodes. Dissect gently the subcutaneous until you reach to superficial fascia (Campers fascia). Incise the fascia gently, lift the fascia and dissect parallel to the lower border of the fascia to separate the superficial inguinal nodes from the subcutaneous tissue. Continue with until you reach the inguinal ligament (upper border of the dissection). Dissect the superficial inguinal lymph nodes off the inguinal ligament starting from the upper edge of the ligament down to the femoral triangle. Lateral circumflex vessels are laterally and the superficial epigastric vessels central \& cranial. Dissect the lymph-nodes off the sartorius muscle fascia starting from upper down to the lower border of the triangle. Dissect the lymph nodes off the adductor longus muscle (medial border). Be aware of the superficial external pudendal vessels. Once the borders identified proceed with separating the groin nodes off the femoral triangle floor proceeding from lateral to medial. Identify the great saphenous vein and dissect carefully until the point of insertion with the femoral vein. For the dissection of the deep femoral lymph nodes, gently dissect the fatty tissue starting from the point of junction between great saphenous vein and femoral vein. Follow the femoral vein through the length of fossa ovalis (usually $3 \mathrm{~cm}$ ). Retract the inguinal ligament cephalad to check for Cloquet's node. Place the drain on the pelvic floor, using silk suture to fix the drain.
Result(s)* Using this step by step technique we minimize the possibility of injuries and offer better healing prognosis with less complications.

Conclusion* This is a safe step by step technique minimizing the risks of injuries and complications of inguinofemoral lymphadenectomy.

\section{AN UNSUAL PRESENTATION OF A GYNECOLOGICAL TUMOR: EXTRAGONADAL YOLK SAC TUMOR OF THE VULVA}

${ }^{1} \mathrm{SA}$ Duru Çöteli*, ${ }^{2} \mathrm{G}$ Yeter, ${ }^{2} \mathrm{~A}$ Usubütün, ${ }^{1} \mathrm{~N}$ Boran. ${ }^{1}$ Etlik Zübeyde Hanım Kadın Hastalıkları Eğitim ve Araştırma Hastanesi, Turkey; ${ }^{2}$ Hacettepe Üniversitesi Tıp Fakültesi, Turkey

\subsection{6/ijgc-2021-ESG0.638}

Introduction/Background* Extragonadal yolk sac tumours (YST) of the external genitalia is a rare malignancy. Up to date 15 cases have been reported in the literature. YST are highly aggressive, however with the use of chemotherapy survival has improved. The disease-free survival in vulvar YSTs has been reported as 15-90 months with the use of chemotherapy. We present a case of vulvar YST that has been managed with local excision and adjuvant chemotherapy.

Methodology Case Report

Result(s)* A 34-year-old woman presented to our institution with a left vulvar mass reported as primary adenocarcinoma of the vulva. She had given birth six months ago and noticed the mass in the last four months. During the examination a left, painless, mobile mass of average $7 \mathrm{~cm}$ was detected on

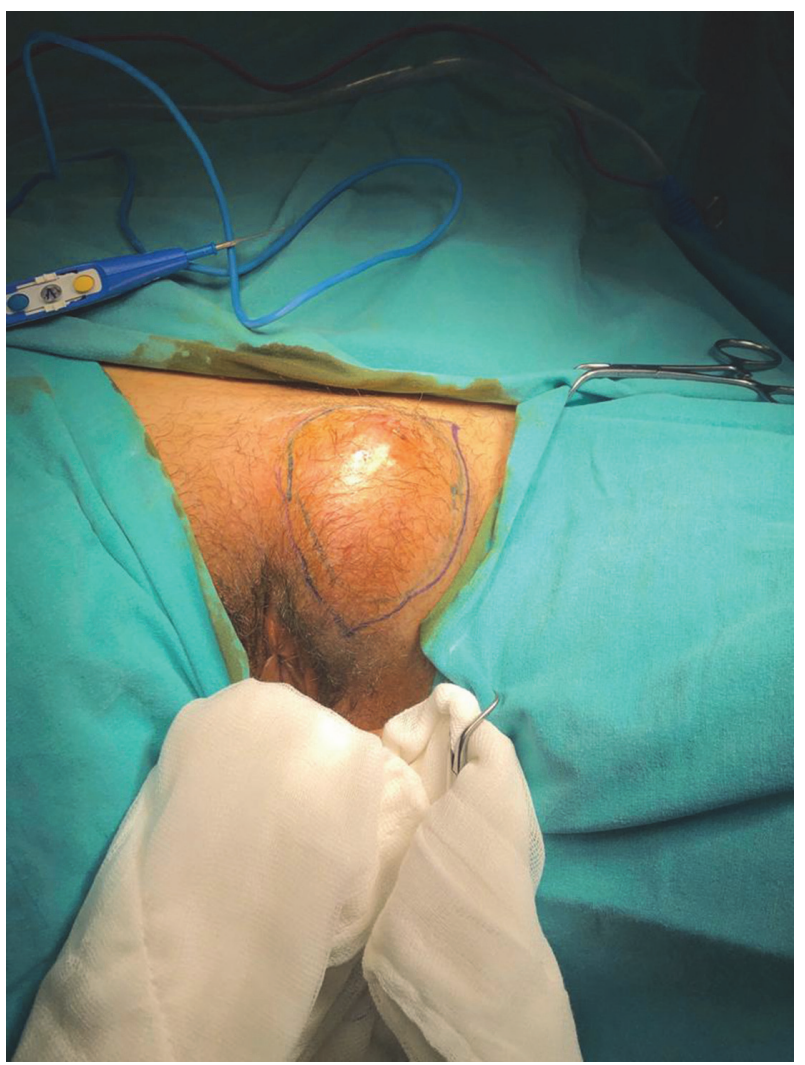

Abstract 1120 Figure 1 